\title{
Pharmacokinetics and Toxicities of Oral Docetaxel Formulations Co-Administered with Ritonavir in Phase I Trials
}

This article was published in the following Dove Press journal: Clinical Pharmacology: Advances and Applications

\author{
Marit Vermunt $\mathbb{D}^{\prime}$ \\ Serena Marchetti ${ }^{2}$ \\ Jos Beijnen 1,3,4 \\ 'Department of Pharmacy \& \\ Pharmacology, The Netherlands Cancer \\ Institute, Amsterdam 1066, CX, the \\ Netherlands; ${ }^{2}$ Department of Clinical \\ Pharmacology, The Netherlands Cancer \\ Institute, Amsterdam 1066, CX, the \\ Netherlands; ${ }^{3}$ Modra Pharmaceuticals B. \\ V., Amsterdam 1083, HN, the \\ Netherlands; ${ }^{4}$ Department of \\ Pharmaceutical Sciences, Utrecht \\ University, Utrecht 3584, CX, the \\ Netherlands
}

Correspondence: Marit Vermunt Department of Pharmacy \& Pharmacology, The Netherlands Cancer Institute,

Plesmanlaan I2I, Amsterdam 1066, CX, the Netherlands

Tel +3I 205122127

Fax +3I 205124753

Email m.vermunt@nki.nl
Introduction: Docetaxel is widely used as intravenous (IV) chemotherapy. Oral docetaxel is co-administered with the cytochrome P450 3A4 and P-glycoprotein inhibitor ritonavir to increase oral bioavailability. This research explores the relationship between the pharmacokinetics (PK) and toxicity of this novel oral chemotherapy.

Methods: The patients in two phase I trials were treated with different oral docetaxel formulations in combination with ritonavir in different dose levels, ranging from 20 to 80 mg docetaxel with 100 to $200 \mathrm{mg}$ ritonavir a day. The patients were categorized based on the absence or occurrence of severe treatment-related toxicity (grade $\geq 3$ or any grade leading to treatment alterations). The docetaxel area under the plasma concentration-time curve (AUC) and maximum plasma concentration $\left(\mathrm{C}_{\max }\right)$ were associated with toxicity.

Results: Thirty-four out of 138 patients experienced severe toxicity, most frequently observed as mucositis, fatigue, diarrhea, nausea and vomiting. The severe toxicity group had a significantly higher docetaxel AUC $(2231 \pm 1405$ vs $1011 \pm 830 \mathrm{ng} / \mathrm{mL} * \mathrm{~h}, \mathrm{p}<0.0001)$ and $\mathrm{C}_{\max }(218 \pm 178$ vs $119 \pm 77 \mathrm{ng} / \mathrm{mL}, \mathrm{p}<0.0001)$ as compared to the patients without severe toxicity. When extrapolated from IV PK data, the patients without severe toxicity had a similar cumulative docetaxel AUC as with standard 3-weekly IV docetaxel, while the $\mathrm{C}_{\max }$ was up to 10 -fold lower with oral docetaxel and ritonavir.

Conclusion: Severe toxicity was observed in $25 \%$ of the patients treated with oral docetaxel and ritonavir. This toxicity seems related to the $\mathrm{PK}$, as the docetaxel $\mathrm{AUC}_{0 \text {-inf }}$ and $\mathrm{C}_{\max }$ were up to twofold higher in the severe toxicity group as compared to the non-severe toxicity group. Future randomized trials will provide a further evaluation of the toxicity and efficacy of the new weekly oral docetaxel and ritonavir regimen in comparison to standard IV docetaxel.

Keywords: oral docetaxel, ritonavir, pharmacokinetics, toxicity

\section{Introduction}

Taxanes are widely used anti-cancer drugs that are currently administered intravenously (IV) in weekly or 3-weekly schedules. ${ }^{1}$ Docetaxel is used to treat prostate, breast and ovarian cancer, non-small lung cancer (NSCLC), gastric cancer and squamous cell carcinoma of the head and neck (SCCHN). ${ }^{2}$ Extensive research has been done to explore the relationship between the pharmacokinetics (PK) and pharmacodynamics of taxanes. ${ }^{3,4}$

Taxane-related toxicity after IV administration is correlated to the PK of taxanes. ${ }^{5}$ For paclitaxel, the occurrence of neutropenia has been related to the 
time during which the plasma paclitaxel concentration exceeded certain thresholds ( $\mathrm{T}>0.05 \mu \mathrm{M}$ and $\mathrm{T}>0.1 \mu \mathrm{M})$ as well as to the area under the plasma concentration-time curve (AUC). ${ }^{5}$ For docetaxel, described predictors for hematological toxicity are the clearance, the AUC and the maximum plasma concentration $\left(\mathrm{C}_{\max }\right)$ and the AUC of the unbound docetaxel fraction. ${ }^{3,6-10}$ In a PK-PD model investigating an equal total dose of IV docetaxel, the AUC and $\mathrm{C}_{\max }$ of docetaxel were not predictive as individual separate parameters, but the maximal moving average docetaxel concentration (a PK parameter that has blending properties of both the AUC and $\mathrm{C}_{\max }$ ) correlated highly with neutropenia. In this model, the scheduling of docetaxel was important for the risk of severe neutropenia. ${ }^{11}$

Although the anti-tumor response to treatment with paclitaxel seems correlated with the PK, this is less clear for docetaxel. ${ }^{5}$ The AUC of docetaxel has been reported as a predictive factor for progression-free survival (PFS) in NSCLC patients, but did not predict survival in another study that enrolled a mixed population with different types of advanced cancer. ${ }^{3,8}$ In the first analysis, using data from multiple Phase II studies with single-agent IV docetaxel, 151 patients with NSCLC had a response rate of $29 \%$ and a median time to progression (TTP) of 99 days (95\% confidence interval 84 to 121 days). ${ }^{3}$ The docetaxel AUC at the first cycle was a significant predictor $(p=0.0232)$ of TTP after adjusting for the cumulative dose, number of disease sites, alpha-1-acid glycoprotein (AAG) levels and performance status. NSCLC patients with a higher than median docetaxel AUC had a lower risk of disease progression, with a $43 \%$ lower progression risk for the patients with a docetaxel AUC at the highest 95th percentile. However, the docetaxel AUC was not predictive for other subpopulations in this study, such as breast cancer. ${ }^{3}$

In clinical practice, docetaxel is usually administered in a 3-weekly IV schedule. However, with weekly docetaxel, less hematological toxicity with a comparable antitumor activity has been observed in NSCLC and metastatic breast cancer patients. ${ }^{12-16}$ Overall, the neutropenia rate is higher (19-48\%) in patients receiving 3-weekly docetaxel in comparison to patients that are treated with weekly docetaxel $(2-16 \%) .{ }^{17}$ Despite this, weekly schedules are advised as a reasonable alternative for vulnerable populations only, such as the elderly and patients with a poor performance status. ${ }^{18,19}$ The docetaxel exposure after weekly and 3-weekly IV treatment was investigated in a comparative study in 46 patients. ${ }^{20}$ The cumulative AUC (dose divided by clearance of week 1, multiplied by 3 ) during 3 weeks with weekly given docetaxel
(35 mg/m $\mathrm{m}^{2}$, infused in 30 minutes) was significantly higher than the AUC (4400 versus $3100 \mathrm{ng} / \mathrm{mL}^{*} \mathrm{~h}$ ) with a 3-weekly schedule $\left(75 \mathrm{mg} / \mathrm{m}^{2}\right.$, infused in 1 hour $)$, in line with the higher administered cumulative dose. Therefore, given the observed lower neutropenia rates observed with weekly treatment, the cumulative docetaxel AUC seems not predictive for hematological toxicity.

Oral anticancer treatment has several advantages above IV administration. It can improve patient comfort and costeffectiveness by avoiding the need for venous punctures and potentially enabling the administration at home. ${ }^{21-27}$ An oral pharmaceutical formulation of docetaxel also avoids the risk of infusion-related reactions associated with polysorbate- 80 present in the IV formulations. ${ }^{28}$ Furthermore, polysorbate- 80 can have pharmacological effects, as it increases the fraction of unbound docetaxel in human plasma in vitro. ${ }^{28}$ Oral treatment with docetaxel does not require polysorbate- 80 as a solvent. However, oral treatment with taxanes is hampered by a low bioavailability, as a result of a poor water solubility of the drugs and a low systemic uptake due to P-glycoprotein (P-gp)mediated efflux and cytochrome P450 A4 (CYP3A4)mediated first-pass metabolism in the intestinal wall and liver. The water solubility of orally given docetaxel was improved by the development of a solid dispersion formulation, named ModraDoc. ${ }^{29}$ In this formulation, polyvinylpyrrolidone (PVP)-K30 and sodium lauryl sulphate (SLS) are used as excipients in absence of ethanol and polysorbate- $80 .{ }^{30}$ By co-administration of an inhibitor of both CYP3A4 and P-gp, such as ritonavir, the systemic uptake of orally given docetaxel (as drinking solution, ModraDoc capsules or ModraDoc tablets) was increased in preclinical and clinical studies. ${ }^{31,32}$ Ritonavir is a potent CYP3A4 inhibitor, known for its extensive use as a booster drug in antiretroviral therapy and has a mild toxicity profile at low doses. ${ }^{33}$

Two clinical phase I studies were conducted to establish the optimal weekly schedule and dose of several docetaxel formulations (drinking solution, capsule and tablets, identified by different ModraDoc codes) co-administrated with ritonavir in patients with advanced solid tumors. $^{34,35}$ In the further development of this novel oral docetaxel treatment, a better understanding of the relationship between docetaxel exposure and toxicity is considered crucial. Therefore, the clinical data of all patients treated with orally given docetaxel in combination with ritonavir in the two above-mentioned phase I trials were combined in the current review, aiming 
(1) to evaluate the incidence and type of toxicities experienced by patients treated in the clinical phase I studies with oral docetaxel formulations co-administered with ritonavir;

(2) to determine the exposure to docetaxel and ritonavir in this population;

(3) to discuss potential correlations between docetaxel exposure and toxicity.

\section{Methods}

\section{Patient Population}

The clinical data from 181 patients enrolled in two phase I trials treated with oral docetaxel as drinking solution (IV Taxotere ${ }^{\circledR}$ formulation given orally), solid dispersion capsules (ModraDoc001, ModraDoc003, ModraDoc004) or solid dispersion tablets (ModraDoc006) co-administrated with ritonavir (Norvir ${ }^{\circledR}$ ) were collected in one database. ${ }^{29}$ The first trial was a multi-armed phase I trial that included 123 patients, treated with different oral docetaxel formulations, IV docetaxel and IV paclitaxel, all in combination with ritonavir (International Standard Randomized Controlled Trial Number (ISRCTN) 32770468 and EudraCT number 2007-004520-20). The results of 67 patients from that trial that were treated in the dose-escalation arms of ModraDoc001 (docetaxel capsule) and ModraDoc006 (docetaxel tablet) in combination with ritonavir were previously published. ${ }^{34}$ The second phase I trial included 58 patients that were treated with different oral docetaxel formulations (ModraDoc001, ModraDoc003, ModraDoc004, ModraDoc005 and ModraDoc006) in combination with ritonavir (clinicaltrial.gov identifier NCT01173913). Data from the 45 patients that received ModraDoc001 capsules and ModraDoc006 tablets in combination with ritonavir were previously published. ${ }^{35}$ In the current analysis, all patients that were treated with oral docetaxel (as drinking solution, capsules or tablets) in combination with ritonavir in the two phase I trials were included for evaluation of the PK-toxicity relationship. Patients allocated to receive paclitaxel, IV administration of docetaxel with ritonavir or who did not receive any study treatment were excluded from the analysis.

The two phase I trials had similar inclusion criteria, identifying a population consisting of adult patients with advanced or metastatic solid tumors, with a World Health Organization performance status (WHO PS) $\leq 2$ and adequate bone marrow, renal and hepatic functions. ${ }^{34,35}$ Both phase I trials enrolled patients after they had been treated with all the systemic treatments that are approved for their type of cancer according to standard of care and if systemic treatment with docetaxel could lead to clinical benefit. In addition, patients with a tumor type for whom docetaxel was indicated according to the standard of care were included. The use of concomitant medications interacting with P-gP or CYP3A4 was not allowed during the study. Patients with bowel obstructions or gastrointestinal motility disorders or any conditions that could influence the intake or absorption of oral medication were excluded from participation in the trial. No maximum to the number of prior palliative anticancer treatments was defined, as long as a 28-day washout period for radio- or chemotherapy was maintained. Prior treatment with taxane-containing chemotherapy was allowed.

In both trials, patients were treated with weekly oral docetaxel and ritonavir until they no longer had clinical benefit from treatment or if toxicity led to patient withdrawal. The doses of oral docetaxel given as drinking solution ranged from 20 to $30 \mathrm{mg}$ a day in combination with ritonavir $100 \mathrm{mg}$. The doses of oral docetaxel as ModraDoc001, ModraDoc003 and ModraDoc004 capsules ranged from 20 to $80 \mathrm{mg}$ docetaxel a day combined with 100 to $200 \mathrm{mg}$ ritonavir a day. ModraDoc006 tablets were administered in doses from 40 to $80 \mathrm{mg}$ docetaxel in combination with ritonavir 100 to $200 \mathrm{mg}$ a day.

Standard supportive care measures according to the protocol were applied for nausea (metoclopramide/domperidon and 5HT3 antagonists, and upon indication dexamethasone and benzodiazepine therapy) and diarrhea (treatment with loperamide). In both studies, the use of hematopoietic growth factors was not allowed.

Both clinical trials were performed in line with the principles of the Declaration of Helsinki. Both clinical trials were approved by the Medical Ethical Committee of the Netherlands Cancer Institute. At enrollment, all patients gave written informed consent for collection and analysis of their clinical and pharmacokinetic data for this research.

\section{Pharmacokinetic Analysis}

Depending on the study, sampling for PK was performed on day $1-3$ of cycle 1,2 or 3 of the weekly treatment, until 48 hours after the morning intake of the oral docetaxel formulation administered in combination with ritonavir. Plasma docetaxel and ritonavir concentrations were measured using a validated liquid chromatography coupled with tandem mass spectrometry (LC-MS/MS) assay, with lower limits of quantification of $0.5 \mathrm{ng} / \mathrm{mL}$ 
for docetaxel and $2.0 \mathrm{ng} / \mathrm{mL}$ for ritonavir. ${ }^{36}$ Non-compartmental methods were used for PK analysis, using validated scripts in the $\mathrm{R}$ software package (version $3.01) .{ }^{37}$ The mean, median, coefficient of variation $(\mathrm{CV})$ and range of docetaxel and ritonavir were calculated for the time to maximal plasma concentration ( $\mathrm{t}$ max $)$, maximum plasma concentration $\left(\mathrm{C}_{\max }\right)$, area under the plasma concentration versus time curve from zero to infinity $\left(\mathrm{AUC}_{0 \text {-inf }}\right)$ and elimination half-life $\left(\mathrm{t}_{1 / 2}\right)$.

To assess the relationship between $\mathrm{PK}$ and toxicity, the AUC $_{0 \text {-inf }}$ and $\mathrm{C}_{\max }$ data of cycles 1 and 2 of all evaluable patients were collected for both docetaxel and ritonavir and the mean values were used for analysis. Unpaired $t$ tests with $\alpha=0.05$ were used to assess statistically significant differences between the $\mathrm{AUC}_{0 \text {-inf }}$ and $\mathrm{C}_{\max }$ of patients with and without severe toxicity.

\section{Toxicity Analysis}

Study visits for safety evaluation were similar in the two trials and included measurements of the vital signs, physical examination, registration of adverse events (AEs) and their relation to the study treatment, concomitant medication and laboratory assessments, including hematology and serum chemistry. Visits occurred weekly at the outpatient clinic for the first 6 weeks, followed by 2-weekly assessments for the subsequent weeks. The US National Cancer Institute's Common Terminology Criteria for AEs (NCI-CTCAE) version 3.0 was used to assess the type and severity of the AEs. Toxicities were assessed as being related to oral docetaxel, ritonavir or both. To assess the relationship between PK and toxicity, the medical records of all evaluable patients were reviewed to collect the type and severity of the AEs, the number of treatments and time of occurring of the AEs, their relationship with the study treatment, dose reductions and reason and timing of discontinuation of study medication. All data were collected in the database. All patients were divided into two groups: "patients without severe toxicity" and "patients with severe toxicity". Severe toxicity was defined as all CTCAE grade $\geq 3$ adverse events, occurring despite appropriate supportive care measures as described in the study protocol, which were considered possibly, probably or definitely related to the study treatment. In addition, all AEs of any grade leading to treatment alteration (treatment delay, dose reduction or study drug discontinuation) were also considered severe toxicity.

\section{Results}

\section{Patients and Study Treatment}

As described in Figure 1, 181 patients were treated in the two phase I studies. Of these patients, 38 received treatment with intravenous docetaxel or paclitaxel. The remaining 143 patients were enrolled for treatment with oral docetaxel and ritonavir, of which 5 patients were not evaluable because of discontinuation before the start of the study treatment or because of incomplete clinical data. Therefore, 138 patients were evaluable for PK and safety.

The baseline characteristics of all patients are described in Table 1. In 75\% (104 out of 138) of the patients, no severe treatment-related toxicity was observed. The age, gender, body surface area (BSA) and the number of prior treatments were not different between the groups with and without severe treatment-related toxicity. Almost half of the patients (65 out of 138) had a tumor type with known potential responsiveness to docetaxel (NSCLC, squamous cell carcinoma of the head and neck (SSCHN) and breast cancer), including 60 patients with NSCLC.

The treatment duration of all patients is described in Figure 2. The median treatment duration was 6 weeks (range 1 to 73 weeks). Of all 138 patients, 20 patients received weekly oral docetaxel with ritonavir for $>18$ weeks. For most tumor types, 18 weeks is the maximum duration of 3-weekly IV docetaxel according to standard of care, as most patients are scheduled for a maximum of 6

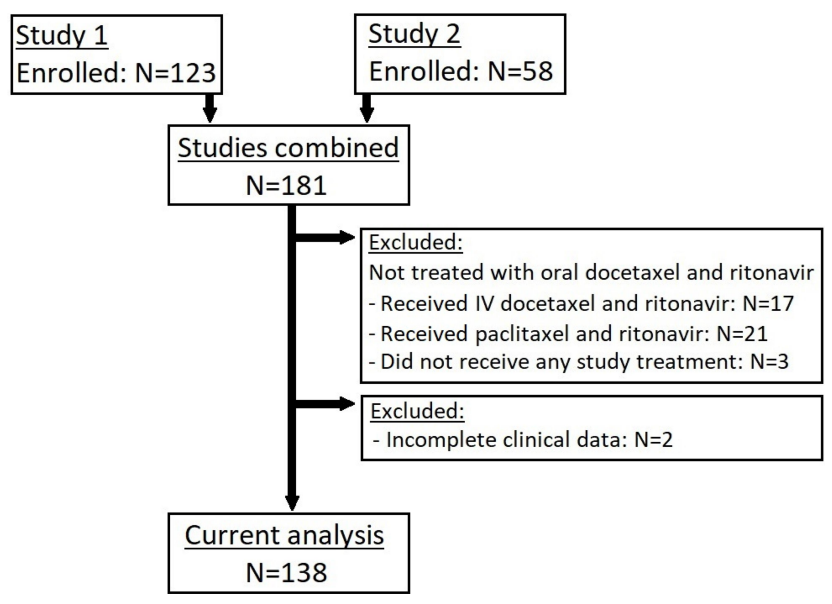

Figure I Included patients.

Notes: Patients included in the analysis. Study I = clinical Phase I study with onceweekly once-daily treatment with oral docetaxel (drinking solution, capsules (ModraDoc00I, ModraDoc003, ModraDoc004) and tablets (ModraDoc006) coadministrated with ritonavir. ${ }^{34}$ Study 2 = clinical phase I study with once-weekly bi-daily treatment with oral docetaxel capsules (ModraDoc00I) and tablets (ModraDoc006) co-administrated with ritonavir. ${ }^{35}$

Note: The number $\mathrm{N}$ represents the number of patients.

Abbreviations: IV, intravenous; PK, pharmacokinetics. 
Table I Characteristics of the Patients Evaluable for Toxicity

\begin{tabular}{|c|c|c|c|}
\hline & $\begin{array}{l}\text { All Patients } \\
(\mathrm{N}=138)\end{array}$ & $\begin{array}{l}\text { Patients without Severe Toxicity } \\
(\mathrm{N}=104)\end{array}$ & $\begin{array}{l}\text { Patients with Severe Toxicity } \\
(\mathrm{N}=34)\end{array}$ \\
\hline $\begin{array}{l}\text { Age } \\
\text { - Mean (range) in years }\end{array}$ & $60(36-79)$ & 59 (37-79) & $6 \mid(36-77)$ \\
\hline $\begin{array}{l}\text { Gender } \\
\text { - Male } \\
\text { - Female }\end{array}$ & $\begin{array}{l}58 \%(N=80) \\
42 \%(N=58)\end{array}$ & $\begin{array}{l}62 \%(N=64) \\
38 \%(N=40)\end{array}$ & $\begin{array}{l}47 \%(N=16) \\
53 \%(N=18)\end{array}$ \\
\hline $\begin{array}{l}\text { BSA } \\
\text { - Mean (range) in } \mathrm{m}^{2}\end{array}$ & $\begin{array}{l}1.95(1.50-2.42) \\
(\mathrm{N}=137)\end{array}$ & $1.96(1.54-2.42)(\mathrm{N}=104)$ & $1.92(1.54-2.38)(\mathrm{N}=33)$ \\
\hline $\begin{array}{c}\text { WHO PS } \\
-0-1 \\
-\geq 2\end{array}$ & $\begin{array}{l}96 \%(N=132) \\
4 \%(N=6)\end{array}$ & $\begin{array}{l}96 \%(N=100) \\
4 \%(N=4)\end{array}$ & $\begin{array}{l}94 \% \mathrm{~N}=32) \\
6 \%(\mathrm{~N}=2)\end{array}$ \\
\hline $\begin{array}{l}\text { Tumor type (frequency }>5 \% \text { ) } \\
\text { - NSCLC } \\
\text { - Urothelial cell ca } \\
\text { - Ovarian ca } \\
\text { - Oesophageal/gastric ca } \\
\text { - Anal ca }\end{array}$ & $\begin{array}{l}43 \%(\mathrm{~N}=60) \\
12 \%(\mathrm{~N}=17) \\
7 \%(\mathrm{~N}=10) \\
7 \%(\mathrm{~N}=10) \\
5 \%(\mathrm{~N}=7)\end{array}$ & $\begin{array}{l}39 \%(\mathrm{~N}=4 \mathrm{I}) \\
14 \%(\mathrm{~N}=15) \\
9 \%(\mathrm{~N}=9) \\
8 \%(\mathrm{~N}=8) \\
5 \%(\mathrm{~N}=5)\end{array}$ & $\begin{array}{l}56 \%(\mathrm{~N}=19) \\
6 \%(\mathrm{~N}=2) \\
3 \%(\mathrm{~N}=1) \\
6 \%(\mathrm{~N}=2) \\
6 \%(\mathrm{~N}=2)\end{array}$ \\
\hline $\begin{array}{l}\text { Sites of metastasis } \\
\text { - Lung/pleural } \\
\text { - Liver } \\
\text { - Abdominal/peritoneal } \\
\text { - Bone } \\
\text { - Cerebral/leptomeningeal }\end{array}$ & $\begin{array}{l}58 \%(\mathrm{~N}=80) \\
20 \%(\mathrm{~N}=27) \\
17 \%(\mathrm{~N}=23) \\
18 \%(\mathrm{~N}=25) \\
7 \%(\mathrm{~N}=10)\end{array}$ & $\begin{array}{l}58 \%(\mathrm{~N}=60) \\
16 \%(\mathrm{~N}=17) \\
20 \%(\mathrm{~N}=21) \\
21 \%(\mathrm{~N}=22) \\
7 \%(\mathrm{~N}=7)\end{array}$ & $\begin{array}{l}59 \%(\mathrm{~N}=20) \\
29 \%(\mathrm{~N}=10) \\
6 \%(\mathrm{~N}=2) \\
9 \%(\mathrm{~N}=3) \\
9 \%(\mathrm{~N}=3)\end{array}$ \\
\hline $\begin{array}{l}\text { Prior treatments } \\
\text { Systemic therapy lines (number) } \\
\text { - Palliative (median (range)) } \\
\text { - Total (median (range)) } \\
\text { Gastrointestinal surgery } \\
\text { - Upper Gl-tract (\% yes) } \\
\text { - Lower Gl-tract (\% yes) } \\
\text { Radiotherapy with Gl-tract in } \\
\text { - field } \\
\text { - Upper Gl-tract (\% yes) } \\
\text { - Lower Gl-tract (\% yes) }\end{array}$ & $\begin{array}{l}\text { I }(0-8) \\
2(0-9) \\
2 \%(N=3) \\
9 \%(N=\mid 2) \\
11 \%(N=15) \\
12 \%(N=16)\end{array}$ & $\begin{array}{l}1(0-8) \\
2(0-9) \\
2 \%(N=2) \\
10 \%(N=10) \\
12 \%(N=12) \\
10 \%(N=10)\end{array}$ & $\begin{array}{l}\text { I (0-7) } \\
\text { I (0-7) } \\
3 \%(N=1) \\
6 \%(N=2) \\
8 \%(N=3) \\
18 \%(N=6)\end{array}$ \\
\hline $\begin{array}{l}\text { Ethnicity } \\
\text { - Caucasian } \\
\text { - Black } \\
\text { - Other }\end{array}$ & $\begin{array}{l}97 \%(\mathrm{~N}=134) \\
\mathrm{I} \%(\mathrm{~N}=2) \\
\mathrm{I} \%(\mathrm{~N}=2)\end{array}$ & $\begin{array}{l}96 \%(\mathrm{~N}=100) \\
2 \%(\mathrm{~N}=2) \\
2 \%(\mathrm{~N}=2)\end{array}$ & $100 \%(N=34)$ \\
\hline
\end{tabular}

Abbreviations: ca, carcinoma; WHO PS, World Health Organization Performance Score; NSCLC, non-small cell lung cancer; GI-tract, gastrointestinal tract; N, number of patients.

IV cycles (except patients with metastatic castration-resistant prostate cancer for whom 3-weekly IV docetaxel is approved as standard of care for a maximum of 10 cycles). ${ }^{38,39}$ Eight patients were treated for $>30$ weeks and three patients received continuous weekly oral docetaxel with ritonavir for more than 1 year. A total of 58 patients $(42 \%)$ experienced clinical or radiological progressive disease according to Response Evaluation Criteria in Solid Tumors (RECIST) before or at the first radiological evaluation at 6 weeks. ${ }^{40}$ Stable disease (SD) during $\leq 3$ months was observed in 15 (11\%) patients. Prolonged SD $>3$ months and partial remission (PR) 


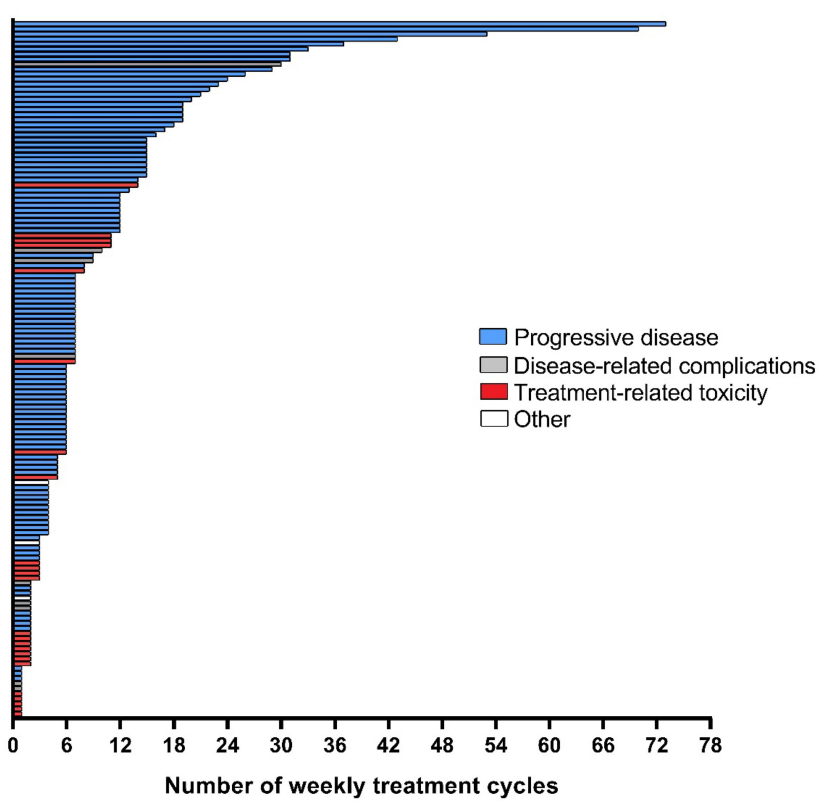

Figure 2 Duration of treatment.

Notes: Duration of continuous weekly treatment with oral docetaxel and ritonavir for I 38 patients treated in the two phase I trials. Each row represents one single patient. The color indicates the reason for discontinuation, ie disease progression (blue), disease-related complications (grey), treatment-related toxicity (red) or other reasons (white) such as a switch of the oral docetaxel formulation.

according to RECIST were observed in 30 (22\%) and 6 (4\%) patients, respectively. None of the patients achieved a complete response according to RECIST. As described in Figure 2, the majority of the patients discontinued study treatment at a certain moment because of progressive disease $(\mathrm{N}=102,74 \%)$ or disease-related complications $(\mathrm{N}=9$, 7\%). Disease-related complications consisted of infections related to obstructive tumours ((peri)anal abscess $(\mathrm{N}=2)$, lung abscess $(\mathrm{N}=1)$, cholangitis $(\mathrm{N}=1)$, urinary infection $(\mathrm{N}=1)$ ), bleeding from tumours (gastrointestinal bleeding $(\mathrm{N}=1)$, hematuria $(\mathrm{N}=1))$, development of a rectovesical fistula $(\mathrm{N}=1)$ and a treatment-refractory disease-related delirium $(\mathrm{N}=1)$. Oral docetaxel/ritonavir was discontinued in $24(17 \%)$ patients because of treatment-related toxicity.

\section{Toxicity}

As described in Table 2, severe toxicities that were considered related to the study medication occurred in $25 \%$ (34 out of 138) of the patients evaluable for the PKtoxicity analysis. The most frequently observed severe AEs were CTCAE grade 3 mucositis (7\%), fatigue $(7 \%)$, diarrhea (4\%), nausea (4\%) and vomiting (4\%), mostly occurring during the first two to four weekly cycles of study treatment. A total of seven patients (5\%) experienced (febrile) neutropenia leading to study drug discontinuation in six patients and continuation with a dose reduction in one patient. Rare late drug-related AEs, each present in only $1 \%$ of the patients beyond 11 weeks of treatment, were chylous fluid retention in the thoracic or abdominal cavity, peripheral fluid retention, fatal pneumonitis and severe skin toxicity.

\section{Pharmacokinetics}

The mean $\mathrm{AUC}_{0 \text {-inf }}$ and $\mathrm{C}_{\max }$ of cycles 1 and 2 were analyzed for 138 patients. These two PK parameters were correlated, as depicted in Figure 3. The relationship between ritonavir and docetaxel exposure is shown in Figure 4. In general, the docetaxel exposure seems higher with higher ritonavir exposure. The exact interpretation of the data is complicated by the use of different docetaxel formulations (drinking solution, capsule or tablet), administration schedules (once or twice daily) and doses (ranging from a weekly daily docetaxel dose of 30-80 mg), co-administered with different ritonavir doses $(100 \mathrm{mg}$ or $200 \mathrm{mg}$ once daily or $100 \mathrm{mg}$ twice daily). Nevertheless, the general picture resembles an increasing docetaxel exposure as a result of a higher ritonavir exposure, compatible with a higher CYP3A4 inhibition by ritonavir.

\section{PK-Toxicity Analysis}

The systemic exposure to docetaxel was significantly higher in patients experiencing severe toxicity as compared to the patient group without severe toxicity, as depicted in Figure 5. The mean docetaxel $\mathrm{AUC}_{0 \text {-inf }}$ was more than twofold higher $(\mathrm{p}<0.0001)$ in patients with severe treatment-related toxicity $(2231 \pm 1405 \mathrm{ng} / \mathrm{mL} * \mathrm{~h}$ $(n=34))$, in comparison to patients who did not experience severe treatment-related AEs $\left(1011 \pm 830 \mathrm{ng} / \mathrm{mL}^{*} \mathrm{~h}\right.$ $(\mathrm{n}=104))$. The mean $\mathrm{C}_{\max }$ of docetaxel was also higher $(\mathrm{p}<0.0001)$ in the severe toxicity group $(218 \pm 178 \mathrm{ng} / \mathrm{mL}$ $(n=34))$ when compared to the patients without severe toxicity $(119 \pm 77 \mathrm{ng} / \mathrm{mL}(\mathrm{n}=104))$.

For ritonavir, the severe toxicity group had a significantly higher mean ritonavir $\mathrm{AUC}_{0 \text {-inf }}(31421 \pm 23107$ $(\mathrm{n}=33)$ vs $\left.\left.17555 \pm 13243(\mathrm{n}=103) \mathrm{ng} / \mathrm{mL}^{*} \mathrm{~h}, \mathrm{p}<0.0001\right)\right)$ and mean $\mathrm{C}_{\max }(2273 \pm 1654(\mathrm{n}=34)$ vs $1633 \pm 1238$ $(\mathrm{n}=103) \mathrm{ng} / \mathrm{mL}, \mathrm{p}=0.0180)$ as compared to the non-severe toxicity group.

\section{Discussion}

In line with IV treatment, the toxicity of orally given docetaxel with ritonavir seems related to the systemic docetaxel exposure. The mean docetaxel $\mathrm{AUC}_{0 \text {-inf }}$ on the established 
Table 2 Severe Toxicities Related to Oral Docetaxel Co-Administrated with Ritonavir

\begin{tabular}{|c|c|c|c|c|}
\hline \multirow{2}{*}{$\begin{array}{l}\text { Severe Toxicities }^{\mathbf{a}} \\
\text { Mucositis } \\
\text { (stomatitis, oesophagitis, gastritis, duodenitis) }\end{array}$} & \multirow{2}{*}{ Grade } & \multirow{2}{*}{$\begin{array}{l}\% \text { of Patients } \\
7 \%(N=9)\end{array}$} & \multicolumn{2}{|c|}{ Number of Cycles ${ }^{c}$ (Median (Range)) } \\
\hline & & & $3(I-I I)$ & Acute \\
\hline Fatigue & 3 & $7 \%(N=9)$ & $4(1-13)$ & \\
\hline Diarrhea & 3 & $4 \%(N=6)$ & $2(1-4)$ & \\
\hline \multirow[t]{2}{*}{ Vomiting } & 2 & $1 \%(N=1)$ & 7 & \\
\hline & 3 & $4 \%(N=6)$ & $2(2-4)$ & \\
\hline \multirow[t]{2}{*}{ Nausea } & 2 & $1 \%(N=I)$ & II & \\
\hline & 3 & $4 \%(N=6)$ & $2(2-4)$ & \\
\hline ASAT/ALAT increase & 3 & $3 \%(N=4)$ & $2(I-2)$ & \\
\hline \multirow[t]{2}{*}{ Febrile neutropenia } & 3 & $2 \%(N=3)$ & $3(2-3)$ & \\
\hline & 4 & $1 \%(N=I)$ & I & \\
\hline \multirow[t]{2}{*}{ Neutropenia } & 2 & $I \%(N=I)$ & 2 & \\
\hline & 4 & $1 \%(N=2)$ & $2(I-2)$ & \\
\hline \multirow[t]{2}{*}{ Thrombocytopenia } & 2 & $1 \%(N=1)$ & 5 & \\
\hline & 3 & $I \%(N=I)$ & 2 & \\
\hline Anorexia & 3 & $2 \%(N=3)$ & $2(I-6)$ & \\
\hline Chylothorax/chylous ascites & 3 & $1 \%(N=2)$ & $20(14-25)$ & \multirow[t]{4}{*}{ Late } \\
\hline Peripheral fluid retention & 3 & $1 \%(N=I)$ & 14 & \\
\hline Pneumonitis & 5 & $1 \%(N=1)$ & 11 & \\
\hline Skin toxicity ${ }^{\mathrm{b}}$ & 3 & $\mathrm{I} \%(\mathrm{~N}=\mathrm{I})$ & 11 & \\
\hline
\end{tabular}

Notes: a CTCAE $\geq$ grade 3 toxicities that were considered (possibly, probably or definitely) related to the study medication or related toxicities of any grade that have led to discontinuation or a dose reduction of the study medication; ${ }^{b}$ Combination of hand-foot syndrome, nail loss, ulcerations on the extremities, diagnosed as either toxicodermia or erythema exsudativum multiforme after skin biopsy analysis; 'Intended as number of cycles administered before the development of severe toxicity. Abbreviations: ASAT, aspartate aminotransferase; ALAT, alanine aminotransferase; N, number of patients.

maximum tolerated dose (MTD) was $1709 \pm 1678 \mathrm{ng} / \mathrm{mL}^{*} \mathrm{~h}$ $(\mathrm{N}=10)$ for the once-daily and $1418 \pm 429 \mathrm{ng} / \mathrm{mL} * \mathrm{~h}(\mathrm{~N}=16)$ for the twice-daily schedule of weekly treatment with oral docetaxel tablets (ModraDoc006) and ritonavir. ${ }^{34,35}$ The safety of the dose levels was investigated by evaluation of dose-limiting toxicities (DLTs) in a classical $3+3$ dose escalation design. DLTs consisted of grade $\geq 3$ toxicities, occurring in the first 4 weeks of treatment. At the MTD, DLTs were allowed in a maximum of 1 out of 6 patients. ${ }^{34,35}$ However, for the current analysis, the goal is not dose-finding but exploring the relationship between $\mathrm{PK}$ and toxicity. Therefore, all toxicity that is considered clinically relevant was taken into account in the current analysis. This has led to a very broad definition for severe treatment-related toxicity, including all CTCAE grade $\geq 3$ AEs and all toxicity of any grade leading to treatment alterations during the complete study treatment. As a consequence, both the acute and the chronic toxicity due to prolonged exposure to oral docetaxel and ritonavir was captured for 138 patients in this analysis, whereas the MTD in both studies was based on the acute DLTs only. Given the broader definition, the incidence of severe treatment-related toxicity is higher in our current analysis. Also, the docetaxel AUC at which this severe toxicity occurred is lower in our current analysis as compared to the docetaxel AUC observed on the established MTD of both studies.

Our observations that the overall toxicity of oral docetaxel and ritonavir is related to the docetaxel AUC, are in line with a recent analysis that was conducted for treatment-related diarrhea in the same patient population. ${ }^{41}$ Preclinical data in mice that were treated with oral and intraperitoneal docetaxel confirmed that this intestinal toxicity is caused by the systemic exposure and not by local intestinal exposure to docetaxel. ${ }^{41}$ 


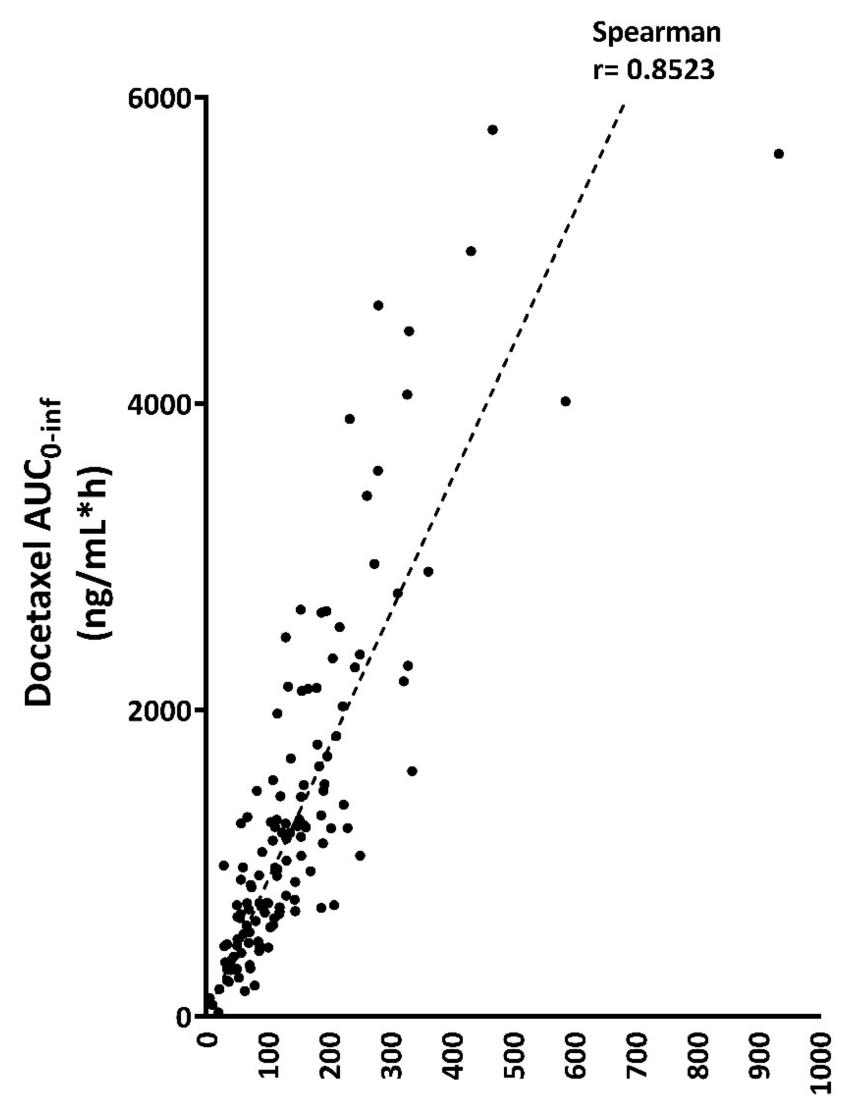

\section{Docetaxel $\mathrm{C}_{\max }$ $(\mathrm{ng} / \mathrm{mL})$}

Figure 3 Correlation of the $\mathrm{C}_{\max }$ and the AUC of docetaxel.

Notes: The relation between the maximum plasma concentration $\left(C_{\max }\right)$ and the area under the plasma concentration versus time curve from zero to infinity $\left(A \cup C_{0 \text {-inf }}\right)$ of docetaxel for 138 patients treated with oral docetaxel plus ritonavir. For both parameters, the mean results of cycles I and 2 of every individual patient were used. The $\mathrm{C}_{\max }$ and $\mathrm{AUC}_{0 \text {-inf }}$ of docetaxel seem correlated, as assessed with the non-parametric Spearman correlation test $(r=0.85)$.

The mean $\mathrm{AUC}_{0 \text {-inf }}$ (calculated as dose divided by clearance) after 3-weekly IV docetaxel treatment (dosed $75 \mathrm{mg} / \mathrm{m}^{2}$ ) was defined as $3340 \mathrm{ng} / \mathrm{mL}^{*} \mathrm{~h}$ in a meta-analysis of 26 studies, including 1150 patients with different types of metastatic solid tumors (excluding prostate cancer). ${ }^{42}$ Another study found an AUC of $3680 \mathrm{ng} /$ $\mathrm{mL} * \mathrm{~h}$, based on 5 studies in over 800 patients receiving 3-weekly IV docetaxel $\left(75 \mathrm{mg} / \mathrm{m}^{2}\right){ }^{43}$ If we extrapolate from these data, the AUC of weekly docetaxel should be around 1100 to $1200 \mathrm{mg} / \mathrm{mL}^{*} \mathrm{~h}$ to reach a comparable cumulative docetaxel exposure in 3 weeks. Although our patients were treated in two dose-escalating phase I studies with treatment started at low doses, this AUC was already achieved in 69 out of $138(50 \%)$ patients.

Although a direct comparison has to be awaited in upcoming randomized trials, the toxicity profile of the

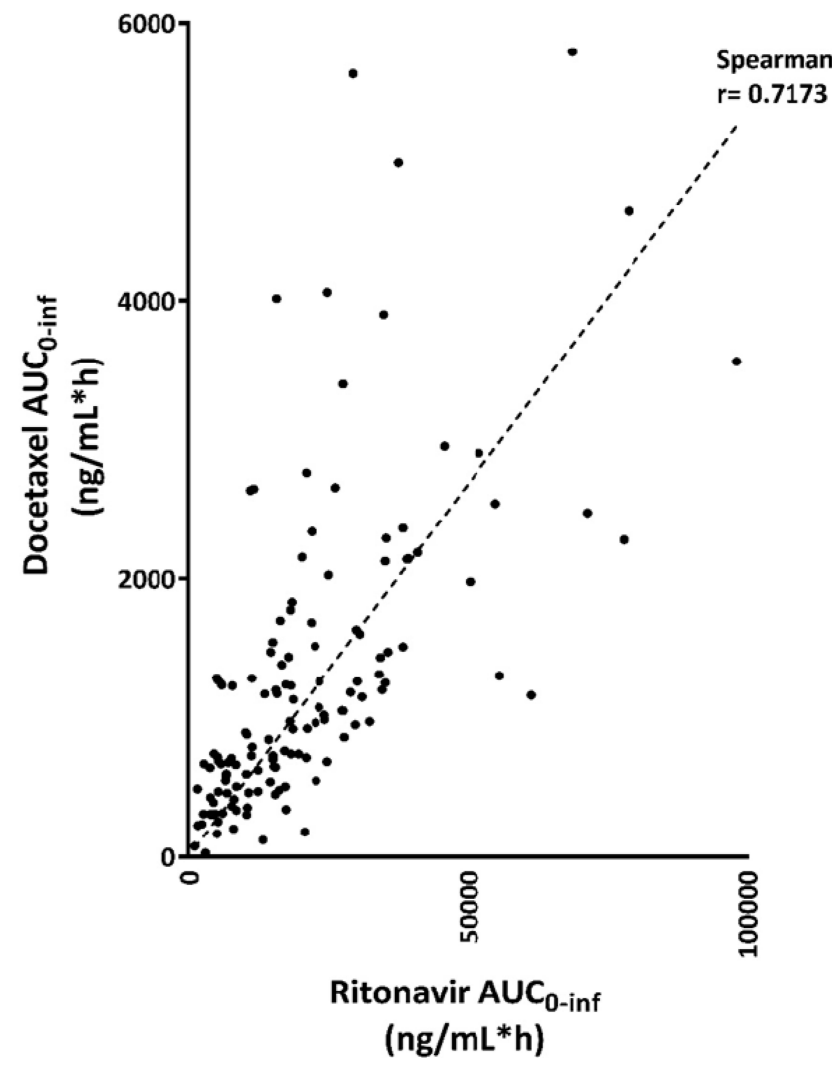

Figure 4 Relation of the exposure to ritonavir versus docetaxel.

Notes: The relation between the AUC of ritonavir versus that of docetaxel for 138 patients treated with oral docetaxel plus ritonavir. For both parameters, the mean results of cycles $I$ and 2 of every individual patient were used. The AUC of docetaxel and ritonavir seem correlated, as assessed with the non-parametric Spearman correlation test $(r=0.72)$.

weekly oral docetaxel treatment seems different from that of 3-weekly IV docetaxel. The severe (febrile) neutropenia rate seems substantially lower, in spite of a higher frequency of low-grade gastrointestinal toxicity with oral docetaxel in combination with ritonavir. ${ }^{8,17,34,35}$ In the patients treated with oral docetaxel and ritonavir, both the AUC and $\mathrm{C}_{\max }$ of docetaxel were significantly higher in patients included in the severe toxicity group. The interpretation of the effect of $\mathrm{C}_{\max }$ in the oral docetaxel treatment is difficult, as the $\mathrm{C}_{\max }$ and $\mathrm{AUC}_{0 \text {-inf }}$ are correlated to each other (Figure 3). However, although the cumulative 3-weekly AUC is comparable, weekly oral docetaxel with ritonavir treatment leads to up to ten-fold lower $\mathrm{C}_{\max }$ values in comparison to standard IV docetaxel (3-weekly $75 \mathrm{mg} / \mathrm{m}^{2}$ ), as described in the published population pharmacokinetic model. ${ }^{44}$ While the $\mathrm{C}_{\max }$ of weekly oral docetaxel with ritonavir is ranging around $200 \mathrm{ng} / \mathrm{mL}$, the $\mathrm{C}_{\max }$ of IV docetaxel ranged from $1910 \mathrm{ng} / \mathrm{mL}$ at a dose of $70 \mathrm{mg} / \mathrm{m}^{2}$ until $2420 \mathrm{ng} / \mathrm{mL}$ at a dose of $85 \mathrm{mg} /$ $\mathrm{m}^{2}{ }^{45}$ Therefore, the low neutropenia rates with weekly 


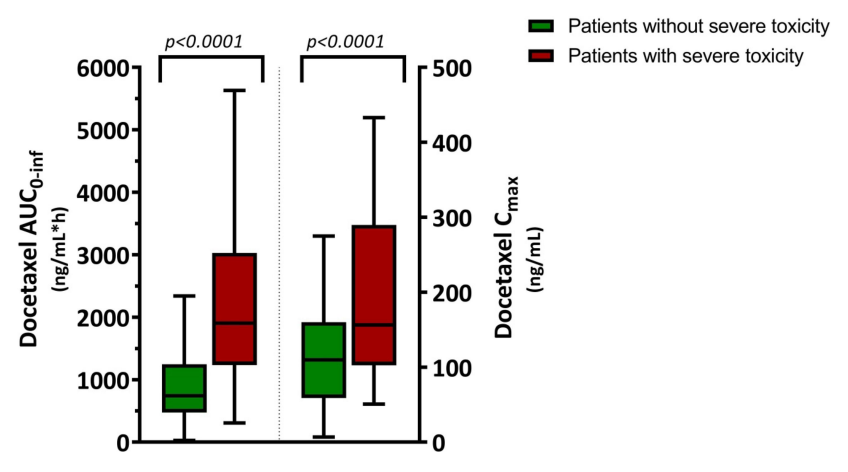

Figure 5 Pharmacokinetic exposure to docetaxel in patients with and without severe toxicity.

Notes: Weekly $\mathrm{AUC}_{0 \text {-inf }}$ (mean of the first two weekly treatment cycles) on the left $\mathrm{Y}$-axis and $\mathrm{C}_{\max }$ of docetaxel on the right $\mathrm{Y}$-axis, in patients without (green boxplots, $\mathrm{N}=104$ ) and with severe toxicity (red boxplots, $\mathrm{N}=34$ ). The boxplots show the median $A \cup C_{0 \text {-inf }}$ of 1905 (25\% percentile 1233 and $75 \%$ percentile 3029 ) for the severe toxicity group (red) and median $\mathrm{AUC}_{0 \text {-inf }}$ of 742 (25\% percentile 474 and $75 \%$ percentile 1247) $\mathrm{ng} / \mathrm{mL}^{*} \mathrm{~h}$ of the group without severe toxicity (green) on the left $Y$-axis. On the right $Y$-axis, the median $C_{\max }$ of 156 (25\% percentile 103 and $75 \%$ percentile 209) for the severe toxicity group, as compared to the group without severe toxicity with a median $C_{\max }$ of 110 (25\% percentile 59 and $75 \%$ percentile 160$) \mathrm{ng} / \mathrm{mL}$. Severe toxicity was defined as all CTCAE grade 3 toxicities and/or toxicities of any grade leading to treatment interruption, discontinuation or dose reduction, that were possibly, probably or definitely related to the study treatment. For both PK parameters, the mean was significantly higher $(p<0.0001$ with two-sided $t$-test, $\alpha=0.05$ ) in the severe toxicity group (mean $A \cup C_{0 \text {-inf }} 2231 \pm$ standard deviation (SD) $1405 \mathrm{ng} / \mathrm{mL}^{*} \mathrm{~h}$ and mean $C_{\max } 218 \pm 178 \mathrm{ng} / \mathrm{mL}$ ) as compared to the group without severe toxicity (mean $\mathrm{AUC}_{0 \text {-inf }} 1011 \pm 830 \mathrm{ng} /$ $\mathrm{mL} * \mathrm{~h}$ and mean $\mathrm{C}_{\max } 119 \pm 77 \mathrm{ng} / \mathrm{mL}$ ).

oral docetaxel and ritonavir treatment, are likely to be explained by the lower $\mathrm{C}_{\max }$ values of docetaxel with oral as compared to IV treatment.

Besides the docetaxel exposure, the exposure to ritonavir was also significantly higher in the patient group experiencing severe toxicity. The correlation between the ritonavir and docetaxel levels is depicted in Figure 4, where higher ritonavir levels might have led to a higher docetaxel exposure. As known from its use in antiretroviral therapy, ritonavir inhibits CYP3A4 at very low doses and the quantity of the CYP3A4 inhibition is dependent on the dose of ritonavir, which itself exhibits non-linear PK. ${ }^{46,47}$ However, in a study in which ritonavir was used as a booster for elvitegravir, the CYP3A4 inhibition (assessed by midazolam clearance) plateaued at a ritonavir dose of $100 \mathrm{mg}$ and an increase to 200 mg did not lead to further boosting. ${ }^{48}$ In our study population, fixed daily ritonavir doses of $100 \mathrm{mg}$ and $200 \mathrm{mg}$ were used, however with different oral docetaxel doses and pharmaceutical formulations. Therefore, it is difficult to explore a dosedependent or PK-dependent relationship between ritonavir and docetaxel PK. In the prior proof of concept studies with oral taxanes combined with a CYP3A4 and P-gp inhibitor, ritonavir was chosen as the most optimal drug above other boosters (eg cyclosporin A, ketoconazole, elacridar and clarithromycin) because of its low toxicity profile. ${ }^{49,50}$ Known toxicities related to ritonavir are nausea, circumoral paresthesia, and elevated levels of hepatic enzymes, observed in patients receiving continuous daily treatment with higher ritonavir doses (starting from $600 \mathrm{mg} /$ day), in contrast to the maximum ritonavir dose of once-weekly $200 \mathrm{mg} /$ day in our study population. ${ }^{51}$ Therefore, it is most likely that the toxicities of the docetaxel-ritonavir combination were not related to high ritonavir levels, but to the docetaxel exposure.

In the severe toxicity group, no differences in baseline characteristics that could result in alterations in the PK or a potential higher vulnerability for docetaxel toxicities, such as higher age, poorer performance status and more intensive prior treatment, were observed. ${ }^{52}$ All patients required adequate baseline hepatic and renal functions for inclusion in the trials. It is known that the PK of docetaxel after IV and oral administration (as docetaxel tablet with ritonavir) is different in patients with metastatic castration-resistant prostate cancer. $^{42,53}$ However, we did not include any prostate cancer patients in the current analysis, as they were not enrolled in the two phase I trials. The intake of co-medication, food or herbal substances leading to potential drug-drug interactions with oral docetaxel and/or ritonavir was prohibited and monitored in the two clinical trials. In both trials, sampling for pharmacogenomics was conducted to detect the presence of relevant single nucleotide polymorphisms (SNPs) in genes encoding for the metabolizing enzymes and drug transporters of docetaxel and ritonavir. ${ }^{5,54,55}$ Preliminary analysis of these SNPs (in genes encoding for P-gp (ABCB1/MDR1), Multidrug Resistance Protein 2 (ABCC2/MRP2), Organic Anion Transporting Polypeptide (OATP) 1B3, CYP3A4, CYP3A5 and CYP2C8) showed no significant effects on the PK, which will be reported separately from this article.

Different studies have investigated the relationship between toxicity after IV docetaxel treatment and high levels of unbound docetaxel and low AAG plasma levels. ${ }^{10,56}$ Low AAG levels were associated with the development of oral mucositis and rash in breast cancer patients and were predictive for response and better overall survival after treatment with IV docetaxel in another study in NSCLC patients. ${ }^{57,58}$ However, the fraction of unbound docetaxel is impacted by polysorbate- 80 in the IV formulation, which is lacking in the oral docetaxel formulation. ${ }^{59}$ Therefore, any impact of AAG might be different for oral treatment and it would have been interesting to determine the unbound docetaxel and AAG concentrations in our patient population as well. Unfortunately, this was not possible according to the protocols of both studies. 
Another interesting analysis would be the relation between the PK and the efficacy of oral docetaxel and ritonavir treatment. The relationship between the PK and the efficacy is currently unclear for treatment with IV docetaxel. Moreover, this is even more complicated in our phase I population, in which approximately half of the patients had a tumor type with proven potential responsiveness to docetaxel. Not only the tumor types, but also the number and types of prior treatments were heterogeneous. For the other half of the patients, no proven beneficial systemic treatment options were left and docetaxel was considered as an anticancer drug with potential benefit. Therefore, the efficacy of oral docetaxel and ritonavir should be ideally assessed in a homogeneous patient population for which treatment with docetaxel is indicated as standard of care. Ongoing randomized trials in homogeneous patient populations, such as metastatic castration-resistant prostate cancer, will provide a direct comparison of the toxicity and efficacy of the new weekly oral docetaxel and ritonavir treatment with standard IV docetaxel in the near future.

\section{Conclusion}

The relationship between the PK of docetaxel and toxicity was investigated in a phase I population of 138 patients, treated with weekly oral docetaxel (Taxotere ${ }^{\circledR}$ given orally, solid dispersion ModraDoc001, ModraDoc003 and ModraDoc004 capsules and the solid dispersion tablet ModraDoc006) co-administered with ritonavir. Although the median treatment duration was 6 weeks, eight patients received a relatively long continuous treatment with weekly oral docetaxel and ritonavir for more than 30 weeks. Of all patients, $75 \%$ did not experience CTCAE grade $\geq 3$ toxicities or other toxicities leading to treatment alterations. The most frequently observed severe toxicities in the remaining $25 \%$ of the patients were mucositis, fatigue, diarrhea, nausea and vomiting. This toxicity seems related to the PK, as the docetaxel $\mathrm{AUC}_{0 \text {-inf }}$ and $\mathrm{C}_{\max }$ were up to twofold higher in the severe toxicity group as compared to the non-severe toxicity group. In comparison to standard 3-weekly docetaxel, the weekly oral docetaxel $\mathrm{AUC}_{0 \text {-inf }}$ (three times) of the patients without severe toxicity was similar, while the $\mathrm{C}_{\max }$ with oral docetaxel and ritonavir was up to 10 -fold lower. This might explain the relatively low neutropenia rates with oral docetaxel and ritonavir. Future randomized trials, comparing standard 3-weekly IV docetaxel and weekly ModraDoc006 with ritonavir, will provide a further evaluation of the toxicity and the efficacy of this new weekly oral docetaxel regimen.

\section{Disclosure}

Jos Beijnen has received a grant for translational research (ZonMw code 40-41200-98-004) for clinical development of oral taxanes. The two trials that were reviewed in this article were conducted as investigator-initiated phase I trials in the Netherlands Cancer Institute. After their completion, Modra Pharmaceuticals BV was founded as a spin-off company of the Netherlands Cancer Institute, focusing on the further clinical development of oral taxanes co-administrated with ritonavir. Jos H. Beijnen is a part-time employee and shareholder of Modra Pharmaceuticals Holding BV and is a patent holder on oral taxane formulations. The other authors report no conflicts of interest in this work.

\section{References}

1. Joerger M. Treatment regimens of classical and newer taxanes. Cancer Chemother Pharmacol. 2016;77(2):221-233. doi:10.1007/ s00280-015-2893-6

2. Montero A, Fossella F, Hortobagyi G, Valero V. Docetaxel for treatment of solid tumors: a systematic review of clinical data. Lancet Oncol. 2005;6(4):229-239. doi:10.1016/S1470-2045(05)70094-2

3. Bruno R, Hille D, Riva A, et al. Population pharmacokinetics/pharmacodynamics of docetaxel in phase II studies in patients with cancer. $J$ Clin Oncol. 1998;16(1):187-196. doi:10.1200/JCO.1998.16.1.187

4. Engels FK, Sparreboom A, Mathot RAA, Verweij J. Potential for improvement of docetaxel-based chemotherapy: a pharmacological review. Br J Cancer. 2005;93(2):173-177. doi:10.1038/sj.bjc.6602698

5. Gerritsen-van Schieveen P, Royer B. Therapeutic drug monitoring group of the French Society of Pharmacology and Therapeutics. Level of evidence for therapeutic drug monitoring of taxanes. Fundam Clin Pharmacol. 2011;25(4):414-424. doi:10.1111/j.14728206.2010.00874.x

6. Bruno R, Vivier N, Veyrat-Follet C. Montay G Rhodes GR. Population pharmacokinetics and pharmacokinetic-pharmacodynamic relationships for docetaxel. Invest New Drugs. 2001;19(2):163-169. doi:10.1023/A:1010687017717

7. Ozawa K, Minami H, Sato H. Logistic regression analysis for febrile neutropenia $(\mathrm{FN})$ induced by docetaxel in Japanese cancer patients. Cancer Chemother Pharmacol. 2008;62(3):551-557. doi:10.1007/ s00280-007-0648-8

8. Charles KA, Rivory LP, Stockler MR, et al. Predicting the toxicity of weekly docetaxel in advanced cancer. Clin Pharmacokinet. 2006;45 (6):611-622. doi:10.2165/00003088-200645060-00004

9. Baker SD, Li J, Ten Tije A, et al. Relationship of systemic exposure to unbound docetaxel and neutropenia. Clin Pharmacol Ther. 2005;77(1):43-53. doi:10.1016/j.clpt.2004.09.005

10. Minami H, Kawada K, Sasaki Y, et al. Pharmacokinetics and pharmacodynamics of protein-unbound docetaxel in cancer patients. Cancer Sci. 2006;97(3):235-241. doi:10.1111/j.1349-7006.2006.00166.x

11. Patel M, Palini S, Chakravarty A, Yang J, Shyu WC, Mettetal JT. Dose schedule optimization and the pharmacokinetic driver of neutropenia. PLoS One. 2014;9(10):e109892. doi:10.1371/journal. pone.0109892

12. Gervais R, Ducolone A, Breton JL, et al. Phase II randomised trial comparing docetaxel given every 3 weeks with weekly schedule as second-line therapy in patients with advanced non-small-cell lung cancer (NSCLC). Ann Oncol. 2005;16(1):90-96. doi:10.1093/ annonc/mdi018 
13. Tabernero J, Climent MA, Lluch A, et al. A multicentre, randomised phase II study of weekly or 3-weekly docetaxel in patients with metastatic breast cancer. Ann Oncol. 2004;15(9):1358-1365. doi:10.1093/annonc/mdh349

14. Rivera E, Mejia JA, Arun BK, et al. Phase 3 study comparing the use of docetaxel on an every-3-week versus weekly schedule in the treatment of metastatic breast cancer. Cancer. 2008;112(7):14551461. doi:10.1002/cncr.23321

15. Schröder CP, de Munck L, Westermann AM, et al. Weekly docetaxel in metastatic breast cancer patients: no superior benefits compared to three-weekly docetaxel. Eur J Cancer. 2011;47(9):1355-1362. doi:10.1016/j.ejca.2010.12.018

16. Stemmler HJ, Harbeck N, Gröll de Rivera I, et al. Prospective multicenter randomized Phase III study of weekly versus standard docetaxel (D2) for first-line treatment of metastatic breast cancer. Oncology. 2010;79(3-4):197-203. doi:10.1159/000320640

17. Engels FK, Verweij J. Docetaxel administration schedule: from fever to tears? A review of randomised studies. Eur J Cancer. 2005;41 (8):1117-1126. doi:10.1016/j.ejca.2005.02.016

18. Lilenbaum R, Rubin M, Samuel J, et al. A randomized phase II trial of two schedules of docetaxel in elderly or poor performance status patients with advanced non-small cell lung cancer. J Thorac Oncol. 2007;2(4):306-311. doi:10.1097/01.JTO.0000263713.38826.8e

19. Biganzoli L, Licitra S, Moretti E, Pestrin M, Zafarana E, Di Leo A. Taxanes in the elderly: can we gain as much and be less toxic? Crit Rev Oncol Hematol. 2009;70(3):262-271. doi:10.1016/j.critrev onc.2008.07.017

20. Baker SD, Zhao M, Lee CKK, et al. Comparative pharmacokinetics of weekly and every-three-weeks docetaxel. Clin Cancer Res. 2004;10(6):1976-1983. doi:10.1158/1078-0432.CCR-0842-03

21. Banna GL, Collovà E, Gebbia V, et al. Anticancer oral therapy: emerging related issues. Cancer Treat Rev. 2010;36(8):595-605. doi:10.1016/j.ctrv.2010.04.005

22. Borner M, Scheithauer W, Twelves C, Maroun J, Wilke H. Answering patients' needs: oral alternatives to intravenous therapy. Oncologist. 2001;6(4):12-16. doi:10.1634/theoncologist.6-suppl_4-12

23. Jensen LH, Osterlind K, Rytter C. Randomized cross-over study of patient preference for oral or intravenous vinorelbine in combination with carboplatin in the treatment of advanced NSCLC. Lung Cancer. 2008;62(1):85-91. doi:10.1016/j.lungcan.2008.02.009

24. Lay Le K, Myon E, Hill S, et al. Comparative cost-minimisation of oral and intravenous chemotherapy for first-line treatment of nonsmall cell lung cancer in the UK NHS system. Eur J Health Econ. 2007;8(2):145-151. doi:10.1007/s10198-006-0034-1

25. Twelves C, Gollins S, Grieve R, Samuel L. A randomised cross-over trial comparing patient preference for oral capecitabine and 5-fluorouracil/leucovorin regimens in patients with advanced colorectal cancer. Ann Oncol. 2006;17(2):239-245. doi:10.1093/annonc/mdj023

26. Liu G, Franssen E, Fitch MI, Warner E. Patient preferences for oral versus intravenous palliative chemotherapy. J Clin Oncol. 1997;15 (1):100-115. doi:10.1200/JCO.1997.15.1.110

27. Payne SA. A study of quality of life in cancer patients receiving palliative chemotherapy. Soc Sci Med. 1992;35(12):1505-1509. doi:10.1016/0277-9536(92)90053-S

28. Ten Tije AJ, Verweij J, Loos WJ, Sparreboom A. Pharmacological effects of formulation vehicles: implications for cancer chemotherapy. Clin Pharmacokinet. 2003;42(7):665-685. doi:10.2165/ 00003088-200342070-00005

29. Sawicki E, Beijnen JH, Schellens JHM, Nuijen B. Pharmaceutical development of an oral tablet formulation containing a spray dried amorphous solid dispersion of docetaxel or paclitaxel. Int J Pharm. 2016;511(2):765-773. doi:10.1016/j.ijpharm.2016.07.068

30. Moes JJ, Koolen SLW, Huitema ADR, Schellens JHM, Beijnen JH, Nuijen B. Pharmaceutical development and preliminary clinical testing of an oral solid dispersion formulation of docetaxel (ModraDoc001). Int J Pharm. 2011;420(2):244-250. doi:10.1016/j.ijpharm.2011.08.041
31. Bardelmeijer HA, Ouwehand M, Buckle T, et al. Low systemic exposure of oral docetaxel in mice resulting from extensive firstpass metabolism is boosted by ritonavir. Cancer Res. 2002;62 (21):6158-6164.

32. Oostendorp RL, Huitema A, Rosing H, et al. Coadministration of ritonavir strongly enhances the apparent oral bioavailability of docetaxel in patients with advanced solid tumors. Clin Cancer Res. 2009;15(12):4228-4233. doi:10.1158/1078-0432.CCR-08-2944

33. Von Hentig N, Haberl A. Safety of pharmacoenhancers for HIV therapy. Expert Rev Clin Pharmacol. 2012;5(5):557-568. doi:10.1586/ecp. 12.45

34. De Weger VA, Stuurman FE, Koolen SLW, et al. A phase I dose escalation study of once weekly oral administration of docetaxel as ModraDoc001 capsule or ModraDoc006 tablet in combination with ritonavir. Clin Cancer Res. 2019;25(18):5466-5474. doi:10.1158/ 1078-0432.CCR-17-2299

35. De Weger VA, Stuurman FE, Hendrikx JJMA, et al. A dose-escalation study of bi-daily once weekly oral docetaxel either as ModraDoc001 or ModraDoc006 combined with ritonavir. Eur $J$ Cancer. 2017;86:217-225. doi:10.1016/j.ejca.2017.09.010

36. Hendrikx JJMA, Hillebrand MJ, Thijssen B, et al. A sensitive combined assay for the quantification of paclitaxel, docetaxel and ritonavir in human plasma using liquid chromatography coupled with tandem mass spectrometry. J Chromatogr B Analyt Technol Biomed Life Sci. 2011;879 (28):2984-2990. doi:10.1016/j.jchromb.2011.08.034

37. R Core Development Team. R: A language and environment for statistical computing. 2009.

38. Fossella FV, DeVore R, Kerr RN, et al. Randomized phase III trial of docetaxel versus vinorelbine or ifosfamide in patients with advanced non-small-cell lung cancer previously treated with platinum-containing chemotherapy regimens. J Clin Oncol. 2000;18(12):2354-2362. doi:10.1200/JCO.2000.18.12.2354

39. Harvey V, Mouridsen H, Semiglazov V, et al. Phase III trial comparing three doses of docetaxel for second-line treatment of advanced breast cancer. J Clin Oncol. 2006;24(31):4963-4970. doi:10.1200/ JCO.2005.05.0294

40. Eisenhauer EA, Therasse P, Bogaerts J, et al. New response evaluation criteria in solid tumors: revised RECIST guideline (version 1.1.). Eur J Cancer. 2009;45(2):228-247. doi:10.1016/j.ejca.2008.10.026

41. Hendrikx JJMA, Stuurman FE, Song JY, et al. No relation between docetaxel administration route and high-grade diarrhea incidence. Pharmacol Res Perspect. 2020;00:e00633.

42. De Vries Schultink AHM, Crombag MBS, Van Werkhoven E, et al. Neutropenia and docetaxel exposure in metastatic castration-resistant prostate cancer patients: a meta-analysis and evaluation of a clinical cohort. Cancer Med. 2019;8(4):1406-1415. doi:10.1002/cam4.2003

43. Engels FK, Loos WJ, Van der Bol JM, et al. Therapeutic drug monitoring for the individualization of docetaxel dosing: a randomized pharmacokinetic study. Clin Canc Res. 2011;17(2):353-362. doi:10.1158/1078-0432.CCR-10-1636

44. Yu H, Janssen JM, Sawicki E, et al. A population pharmacokinetic model of oral docetaxel coadministered with ritonavir to support early clinical development. J Clin Pharmacol. 2020;60(3):340-350. doi:10.1002/jcph.1532

45. Extra JM, Rousseau F, Bruno R, Clavel M, Le Bail N, Marty M. Phase I and pharmacokinetic study of Taxotere (RP 56976; NSC 628503) given as a short intravenous infusion. Cancer Res. 1993;53 (5): 1037

46. Greenblatt DJ, Harmatz JS. Ritonavir is the best alternative to ketoconazole as an index inhibitor of cytochrome P450-3A in drug-drug interaction studies. Br J Clin Pharmacol. 2015;80(3):342-350. doi:10.1111/bcp. 12668

47. Eichbaum C, Cortese M, Blank A, Burhenne J, Mikus G. Concentration effect relationship of CYP3A inhibition by ritonavir in humans. Eur J Clin Pharmacol. 2013;69(10):1795-1800. doi:10.1007/s00228-013-1530-8 
48. Mathias AA, West S, Hui J, Kearney BP. Dose-response of ritonavir on hepatic CYP3A4 activity and elvitegravir oral exposure. Clin Pharmacol Ther. 2009;85(1):64-70. doi:10.1038/clpt.2008.168

49. Malingre MM, Richel DJ, Beijnen JH, et al. Coadministration of cyclosporine strongly enhances the oral bioavailability of docetaxel. $J \quad$ Clin Oncol. 2001;19(4):1160-1166. doi:10.1200/ JCO.2001.19.4.1160

50. Hendrikx JJMA, Lagas JS, Wagenaar E, et al. Oral co-administration of elacridar and ritonavir enhances plasma levels of oral paclitaxel and docetaxel without affecting relative brain accumulation. $\mathrm{Br} J$ Cancer. 2014;110(11):2669-2676. doi:10.1038/bjc.2014.222

51. Danner SA, Carr A, Leonard JM, et al. A short-term study of the safety, pharmacokinetics, and efficacy of ritonavir, an inhibitor of HIV-1 protease. European-Australian Collaborative Ritonavir Study Group. $N$ Engl J Med. 1995;333(23):1528-1533. doi:10.1056/ NEJM199512073332303

52. Nieuweboer AJ, De Morrée ES, De Graan AJ, Sparreboom A, De Wit $\mathrm{R}$, Mathijssen RH. Inter-patient variability in docetaxel pharmacokinetics: a review. Cancer Treat Rev. 2015;41(7):605-613. doi:10.1016/ j.ctrv.2015.04.012

53. Vermunt M, Robbrecht D, Devriese L, et al. ModraDoc006, an oral docetaxel formulation in combination with ritonavir (ModraDoc006/ $\mathrm{r}$ ), in metastasized castration-resistant prostate cancer (mCRPC): a multicenter phase I study. ASCO 2020 Genitourinary Cancer Symposium. J Clin Oncol. 2020;38(suppl6):79. doi:10.1200/ JCO.2020.38.6_suppl.79
54. Frederiks CN, Lam SW, Guchelaar HJ, Boven E. Genetic polymorphisms and paclitaxel- or docetaxel-induced toxicities: a systematic review. Cancer Treat Rev. 2015;41(10):935-950. doi:10.1016/j. ctrv.2015.10.010

55. Bosch TM, Huitema ADR, Doodeman VD, et al. Pharmacogenetic screening of CYP3A and ABCB1 in relation to population pharmacokinetics of docetaxel. Clin Cancer Res. 2006;12(19):5786-5793. doi:10.1158/1078-0432.CCR-05-2649

56. Kenmotsu H, Imamura $\mathrm{C}$, Ono A, et al. The effects of advanced age and serum alpha1-acid glycoprotein on docetaxel unbound exposure and dose-limiting toxicity in cancer patients. $\mathrm{Br} J$ Clin Pharmacol. 2017;83(11):2416-2425. doi:10.1111/bcp.13354

57. Jabir RS, Ho GF, Annuar MABA, Stanslas J. Plasma alpha-1-acid glycoprotein as a potential predictive biomarker for non-haematological adverse events of docetaxel in breast cancer patients. Biomarkers. 2018;23(2):142-146. doi:10.1080/ 1354750X.2017.1334152

58. Bruno R, Olivares R, Berille J, et al. Alpha-1-acid glycoprotein as an independent predictor for treatment effects and a prognostic factor of survival in patients with non-small cell lung cancer treated with docetaxel. Clin Cancer Res. 2003;9(3):1077-1082.

59. Loos WJ, Baker SD, Verweij J, Boonstra JG, Sparreboom A. Clinical pharmacokinetics of unbound docetaxel: role of polysorbate 80 and serum proteins. Clin Pharmacother. 2003;74(4):364-371.

\section{Publish your work in this journal}

Clinical Pharmacology: Advances and Applications is an international, peer-reviewed, open access journal publishing original research, reports, reviews and commentaries on all areas of drug experience in humans. The manuscript management system is completely online and includes a very quick and fair peer-review system, which is all easy to use. Visit http://www.dovepress.com/testimonials.php to read real quotes from published authors. 